\title{
Prólogo La Política: \\ deliberación, técnica y movimiento
}

\author{
Luis Eduardo Thayer Correa
}

Universidad de Los Lagos, Santiago, Chile. Email: eduardo.thayer@gmail.com

\author{
Juan Pablo Paredes P.
}

Universidad Diego Portales, Santiago, Chile. Email: juan.paredes@udp.cl

\section{Antonio Elizalde $\mathrm{H}$.}

Universidad Bolivariana, Santiago, Chile. Email: antonio.elizalde@gmail.com

La racionalidad técnica y el pensamiento experto aparecen hoy como el principal instrumento para legitimar la toma de decisiones en el campo de la política. El proceso de racionalización de todas las esferas de la vida que anunciara hace poco más de un siglo Max Weber, encuentra la política contemporánea, un territorio fértil para su reproducción. Las democracias latinoamericanas no están exentas de esta dinámica de reducción de lo político a lo técnico, que traduce los conflictos inherentes a la construcción del espacio público, en problemas contingentes sobre la definición del instrumento apropiado. Esta arremetida de la técnica en el espacio público, pospone el enfrentamiento de acciones y discursos que buscan apropiarse y reconstruir lo público, a favor de una ecuación primaria orientada a depurar un espacio inmunizado ante la controversia. La arremetida de la técnica nos pone así frente al confinamiento de la política a una pura cuestión de medios, no ya de fines. Y es que la reducción de la política a lo técnico implica excluir a los fines de toda discusión. El fin para la técnica no es un problema sino un principio que de facto neutraliza la acción y prefigura el discurso.

Bajo este prisma podemos decir que la ausencia de una pregunta por el sentido (de la acción y el discurso) tal como planteara Heidegger es ya una respuesta a esa pregunta. En nuestra sociedad, la chilena y en parte importante de las sociedades latinoamericanas, esta respuesta encuentra su contenido casi exclusivamente en el objetivo del crecimiento económico y el abultamiento del ingreso per-cápita. El interés común queda así enlazado al dogma del crecimiento, que promete un destino de bienestar general. El interés común, como el ser entre los otros (inter homines esse), que Arendt identificara como el eje de la política, y que implica una apertura del espacio público a al destino impredecible marcado por el encuentro con el otro, es clausurado de antemano por la anteposición de un interés especifico, que se presenta como universal. 
Esta reformulación del interés común impone un problema de vital importancia teórica y política. En la senda de Habermas, cabe preguntarse por la naturaleza ideológica y por ende particular del fin que la técnica presenta como universal. Interrogante a la que cabría sumar un cuestionamiento de la condición ideológica de la misma técnica como el recurso hegemónico de aproximación a lo público. Más allá de los dilemas teóricos que abre esta línea de preguntas, constituye una clave de interpretación de la forma en que los conflictos que se expresan en el escenario político regional, tienden a encauzarse hacia deliberaciones expertas. Esta clave nos permite pensar por ejemplo en las respuestas técnicas que ofrecen obstinadamente los gobiernos, a movilizaciones y demandas que interpelan al Estado desde argumentos y posiciones políticas controversiales. La reducción de la política a la técnica implica en este sentido, la traducción forzosa de todos los lenguajes posibles, al lenguaje unívoco del pensamiento experto. La técnica impone así los términos de la discusión, y cualquier otro lenguaje es deslegitimado por su incompetencia experta. Esta clausura de los términos del debate, tiene como consecuencia directa la exclusión del espacio público de todo discurso planteado en otros términos, y por tanto de los actores que formulen interpelaciones políticas. La tecnificación de la política contribuye así a reproducir y consolidar la crisis de representación que afecta a parte importante de los sistemas políticos latinoamericanos.

Estos problemas políticos motivan en concreto preguntas del tipo ¿cómo influye actualmente el pensamiento experto en la resolución de problemas públicos en las democracias latinoamericanas?; ¿qué conexiones se pueden encontrar entre los argumentos técnicos y el interés de los actores sociales que se ven afectados por las decisiones que se toman en virtud de esos argumentos?; ¿hasta qué punto la deliberación en el espacio público en la región está mediado por una traducción de los problemas políticos a problemas técnicos? Desde una mirada teórica por su parte teórica surgen preguntas como ¿en qué sentido puede reconocerse en el proceso de tecnificación de la política una transformación del sentido de la democrática y el espacio público?, o ¿es acaso una condición propia de las sociedades modernas el caminar hacia una imposición del lenguaje y el pensamiento técnico o es el síntoma de una crisis de la política en la modernidad?, ¿¿es la técnica una nueva forma de ejercer la hegemonía en los sistemas políticos o está asociada a modelos de desarrollo específicos?

Desde distintos puntos de vistas los trabajos de teóricos sociales contemporáneos como el alemán Ulrich Beck, el catalán Manuel Castells, el norteamericano Daniel Bell o el británico Anthony Giddens, influidos todos en alguna medida por la mirada weberiana, apuntan en dirección de estas preguntas. Giddens por ejemplo al introducir la noción de sistemas expertos, sitúa a la ciencia y al pensamiento técnico como el eje que ordena las concepciones de mundo que imperan en la actualidad. El pensamiento experto sería desde esta perspectiva no solo un principio de legitimación de las decisiones políticas, sino también un supuesto para la organización de la vida íntima intima, y de las relaciones en las organizaciones e institu- 
ciones intermedias. No está sin embargo aquí nuestro interés por esta noción, sino en la idea que las respuestas que los sistemas expertos ofrecen al público serán inevitablemente superadas por nuevas respuestas de caducidad. Esta idea es de vital importancia pues permite cuestionar el carácter trascendente y definitivo con que el pensamiento experto presenta sus respuestas. Si Habermas nos ofrece la posibilidad de cuestionar la pretensión universalista de la técnica, Giddens nos permite suponer que la pretensión de verdad con que se presenta toda solución experta en el espacio público (pero también en el privado), es inherentemente provisoria. Ambas miradas complementarias abren un camino claro para poner en tela de juicio la hegemonía de la técnica en el espacio público, y mostrar las formas en que el pensamiento experto obscurece su dimensión política. El propósito de la convocatoria abierta para el número 32 de POLIS Revista Latinoamericana La Política: deliberación, técnica y movimiento, apunta en esta dirección.

La sección lente de aproximación la abre el artículo de Francisco Báez "Lo colectivo, lo técnico y lo político: algunos apuntes sobre la necesidad de la deliberación en la construcción de lo público", en el que desde un enfoque teórico, se aborda el problema de la provisión de bienes públicos a partir de criterios técnicos, destacando que la naturaleza eminentemente política y colectiva se ve apañada por el pensamiento técnico. Lo sigue el trabajo de Verónica Baduino "Burguesía nacional y Estado: la acción política de la Unión Industrial en Argentina durante la Revolución Argentina (1966-1969), en el que desde una perspectiva politológica la autora da cuenta de la relación entre la burguesía y Estado en Argentina entre 1966 y 1969, situando el proceso de racionalización de la política en la lógica de los intereses de clase.

"Por una Ética de la Gestión Pública” se titula el trabajo de Juan Félix Burotto Pinto y de Francisco Ganga en que debaten la complejidad del acercamiento entre ética y gestión pública, indagando las posibles ideologizaciones que se alojan tanto en una y otra disciplina.

A su vez Giselle Davis en su artículo "La generación de recambio político y la nueva sociedad civil ¿quién lidera a quien?” busca conocer cuál es el potencial de la generación de relevo de los partidos políticos para adaptarse a los cambios sociales y representar a la nueva sociedad civil. Concluye que la condición intergeneracional, la visión heterocrítica frente a las formas de reproducción del poder político y la necesidad de legitimidad social favorecen formas distintas de hacer política que se asocian a la democracia de audiencia, la transversalidad de las alianzas y del territorio. A continuación el trabajo de Carolina Muñoz, Paula Miranda y Rodrigo Flores, titulado "Observando las alianzas de colaboración entre organizaciones sin fines de lucro y organizaciones estatales chilenas", presenta los resultados de una investigación que busca dar cuenta de las condiciones y dificultades que limitan y potencian la relación entre el Estado y las organizaciones no gubernamentales, de cara a la implementación de políticas sociales. En sus conclusiones apunta a revisar los puntos críticos 
de esa relación bajo el supuesto del aporte que pueden realizar estos organizamos de la sociedad civil en el marco de las políticas públicas.

El trabajo de Francesco E. Penaglia "La paradoja del poder: ¿elitización o empoderamiento colectivo?, aborda justamente la disyuntiva de lo que el autor denomina la paradoja del poder, cuando esté se encuentra en la sociedad civil activa proyectada en movimientos sociales. Esta paradoja estaría en la dualidad entre un ejercicio conducente a la mayor participación en la construcción del espacio publico, o en su instrumentación por parte de una minoría que lidera al colectivo canalizando la acción hacia sus propios intereses. Por su parte Juan Pablo Pinilla en "Think Tanks, saber experto y formación de agenda política en el Chile actual” ofrece un análisis sistemático del papel desempeñado por los centros de pensamiento orientados a las políticas públicas en el chile post-dictatorial. A partir de la elaboración de un mapa político de estos centros se da cuenta de la influencia que han tenido áreas específicas y diferenciadas del campo político nacional.

Continúa la sección el trabajo de M. Radrigán, A.M. Dávila y F. Penaglia "Gestión y liderazgos en los emprendimientos sociales: el caso del sector no lucrativo chileno", en el que se exponen los resultados de una investigación empírica, en la que se vuelva sobre la relación del Estado con las organizaciones no gubernamentales. En el artículo se postula la necesidad de una coordinación entre ONGs, Estado y otras entidades de la sociedad como Universidades o instituciones privadas, a la vez que se realiza una lectura de las dinámicas internas y organizativas que pueden contribuir al fortalecimiento del papel de estas organizaciones. El articulo de Álvaro Ramis “Asediar la fortaleza sin ánimo de conquista. La incidencia política de la sociedad civil en Habermas" aborda desde un enfoque teórico y asumiendo una mirada crítica, el concepto de sociedad civil que ofrece J. Habermas, en función de observar las potencialidades que tiene para la democracia deliberativa poniendo en relieve las nociones de comunicación y opinión pública.

Juan Sandoval, presenta el trabajo "Representaciones del sujetociudadano en los discursos del saber-experto en Chile” en un registro similar al articulo de Pinilla aludido, en este el autor analiza los supuestos ideológicos y las perspectivas subjetivas que se encuentran implícitas en los discursos institucionales de algunos centros de pensamiento experto chilenos. A partir del análisis se identifican dos perfiles diferenciados, el "sujeto post-ciudadano" y el sujeto "neo-ciudadano". A continuación el articulo de Graciela Tonón "Las relaciones universidad-comunidad: un espacio de reconfiguración de los público” pone en escena las potencialidades que tiene para la construcción del espacio público la articulación de una relación de sinergia entre la sociedad civil y las universidades. Se alude en este sentido a la necesidad de pensar la producción del conocimiento en asociación con las necesidades y aspiraciones de la comunidad, como una forma de democratización del saber. 
El artículo de Jorge Vergara Vidal Operación y movilización. Formas de acción colectiva pre-elíticas en la Falange Nacional chilena (1935-1957), analiza desde una perspectiva histórica las dinámicas institucionales y políticas que se encuentran en la base de dos tipos de "operación”, en la acción de un partido político en proceso de formación. Una orientada ideológicamente por principios doctrinarios y otra dirigida instrumental y pragmáticamente hacia fines específicos. Cierra la sección el artículo presentado por M. Yopo, S. Rivera y Gabriela Peters “Individuación y políticas sociales en Chile. Sobre la experiencia de nuevas propietarias en la comuna de Lo Espejo". En este se aborda el problema de las políticas de vivienda actuales en Chile, desde el punto de vista de la teoría de la individuación. Desde este enfoque teórico se aborda desde una estrategia cualitativa la realidad de las nuevas propietarias en la comuna de Lo Espejo, de la Región Metropolitana.

En la sección Cartografías Para el Futuro, se publica el trabajo de Francisco Lizcano Fernández, “Conceptos de ciudadano, ciudadanía y civismo”. En Proyectos y Avances de Investigación por su parte se incluyen los trabajos de Enrique Aliste y Violeta Rabi "Concebir lo socio-ambiental: representación y representatividad en los discursos sobre el desarrollo"; Gabriel Cid, "La nación bajo examen. La historiografía sobre el nacinoalismo y la identidad nacional en el siglo XIX chileno"; María José Rosende "A democracia como transformação global da sociedade e dos indivíduos em Norbert Elias”; M. Alejandra Energici, J. Antonio Román, Claudio Ramos y Sebastián Ibarra "Solidaridad en la gubernamentalidad liberal avanzada: un análisis en piezas publicitarias”; Jorge Motealegre Iturra “Archipiélagos virtuales: internet y registros de memorias en la sociedad líquida”; Elizabeth Olmos-Martínez, "Evaluación de la política pública para el sector pesquero en el noroeste mexicano: análisis económico y prospectivo"; Felipe Orellana Gallardo "Fundamentos y pentecostalismo como expresión de religiosidades antagónicas: un significativo lazo en común”; Cristián Ovando y Sergio González "La política exterior chileno-boliviana en la década de 1950 mirada desde la región de Tarapacá. Una aproximación desde el diálogo entre las teorías de las percepciones y el realismo clásico"; cerrando con el trabajo de Francisco Ther “Antropología del territorio”.

El número presenta, además, Reseñas especializadas de "Hibridismo Cultural" de Peter Burke, escrita por Jorge Bowen; de "Construcción estatal, orden oligárquico y respuestas sociales: Argentina y Chile, 1840-1930” editado por Ernesto Bohoslavsky y Milton Gordon, presentada por Jorge Gaete; del libro "La expresión de lo interno" de David H. Finkelstein, escrita por María G. Navarro, y finalmente la reseña del libro de Joaquín García Roca "Reinvención de la exclusión social en tiempos de crisis” escrita por Víctor Renes. 